\title{
Weight of the Human Kidney - A Study on 70 Autopsy Cases
}

\author{
Fatema Zohora ${ }^{1}$, Abu Sadat Mohammad Nurunnabi², Dilruba Siddiqua ${ }^{3}$ \\ Hasna Hena ${ }^{4}$, Hosna Ara Perven ${ }^{5}$, Shamim Ara ${ }^{6}$
}

\begin{abstract}
Background: Variations in weight of the kidney in different populations and in different age groups are evident. Objective: The aim of the present study was to find out age related changes in weight of the kidney in a Bangladeshi population and compare with previous local and foreign studies. Materials and method: This cross-sectional study was done in the Department of Anatomy, Dhaka Medical College, Dhaka, Bangladesh from July 2008 to June 2009, based on collection of 140 post mortem human kidneys collected from 70 unclaimed dead bodies which were in the morgue under examination in the Department of Forensic Medicine of same institute. All the samples were divided into three different age groups - A (10-19 years), B (20-39 years) and C (40-59 years), and the weight of each kidney was measured by using a digital balance and recorded. Results: The weight of the right and left kidneys were found $86.18 \pm 0.32 \mathrm{gm}$ and $86.10 \pm 0.10 \mathrm{gm}$ in group A, $102.25 \pm 7.64 \mathrm{gm}$ and $101.96 \pm 7.27 \mathrm{gm}$ in group $B$, $95.59 \pm 0.75 \mathrm{gm}$ and $95.19 \pm 1.24 \mathrm{gm}$ in group $C$ respectively. No difference was found between the right and left kidneys in any group. However, statistically significant differences were evident among age groups. Conclusion: The weight of the kidney was found to increase up to 4th decade of life and then declined with further advancing age.
\end{abstract} Keywords: Human kidney; weight of kidney.

Delta Med Col J. Jan 2016;4(1):31-34

\section{Introduction}

The kidney hosts dramatic alterations in its structure and functions with advancing age including a profound reduction of its weight. ${ }^{1}$ The kidney is characterized by the intensive processes of maturation, but also by changes of involution.
These processes begin during the fetal life when predominate the process of maturation and some changes of involution, and continue after birth. After birth there is a process of the structural maturation of the kidney; it reaches its full

1. Assistant Professor of Anatomy, OSD, Directorate General of Health Services (DGHS), Dhaka, Bangladesh.

2. Assistant Professor of Anatomy, OSD, Directorate General of Health Services (DGHS), Dhaka, Bangladesh.

3. Associate Professor, Dept. of Anatomy, Ibn Sina Medical College, Dhaka, Bangladesh.

4. Associate Professor, Dept. of Anatomy, East-West Medical College, Dhaka, Bangladesh.

5. Associate Professor, Dept. of Anatomy, The Medical College for Women \& Hospital, Uttara, Dhaka, Bangladesh.

6. Professor \& Head, Dept. of Anatomy, Dhaka Medical College, Dhaka, Bangladesh.

Correspondence: Dr. Fatema Johora. e-mail: fatemajohora1973@gmail.com 
anatomical maturity by the third-fourth decade of life. ${ }^{2,3}$ From there on the human kidney is characterized by the changes of involution. These changes of involution are found in all anatomical segments of the kidney and initially they are slow but after the end of sixth decade they are more rapid in progression. ${ }^{2,4}$ The changes of involution can be separate, but they can coincide with renal diseases.2,5 However, studies also revealed that age, sex, and race had no additional impact on kidney weight except body built i.e. body surface area. ${ }^{6}$ Hence, the population based study has become a field of interest for the researchers who are working on morphological changes in aging kidney and its functional correlation. Moreover, it has been observed by various researchers that the dimensions of different organs in Bangladeshi population have got variations from those of the western population. ${ }^{7}$ Hence, the present study was designed to see the variations in weight of kidney with increasing age in a Bangladeshi population and to compare with previous local and foreign studies.

\section{Materials and method}

This cross-sectional study was done in the Department of Anatomy, Dhaka Medical College, Dhaka, Bangladesh from July 2008 to June 2009, based on collection of 140 post mortem human kidneys collected from 70 unclaimed dead bodies which were in the morgue under examination in the Department of Forensic Medicine of the same institute. All the samples were collected from medicolegal cases excluding poisoning, any cutting or crushing injury to the kidneys, kidney found in one side or grossly abnormal in shape/size and from patients suffering from any kidney disease. For convenient description of changes in weight of the kidney in relation to age, the collected samples were divided into three age groups including A (10-19 years), B (20-39 years) and C (40-59 years), according to Darmady et al. ${ }^{8}$ (Table I). The kidney was taken and its outer surface was dried with blotting paper. Then it was weighed by means of a digital balance (SCIENTECH ZSA 210, made in USA) in grams.
All data were recorded and processed. The comparison of weight of kidneys between right and left side was done by unpaired Student's ' $t$ ' test and the comparison of between different groups was done by One-way ANOVA. All the statistical analyses were done by using SPSS, version 13.0 for Windows. This study was approved by the Ethical Review Committee of Dhaka Medical College, Dhaka, Bangladesh.

Table I: Age distribution of the samples of the present study $(n=140)$

\begin{tabular}{cccc}
\hline Age group & $\begin{array}{c}\text { Age limit } \\
\text { in years }\end{array}$ & \multicolumn{2}{c}{ Number of samples } \\
Right kidney & Left kidney \\
\hline A & $10-19$ & 12 & 12 \\
B & $20-39$ & 43 & 43 \\
C & $40-59$ & 15 & 15 \\
\hline
\end{tabular}

\section{Results}

The weight of the right and left kidneys were found $86.18 \pm 0.32 \mathrm{gm}$ and $86.10 \pm 0.10 \mathrm{gm}$ in group A (10-19 years), $102.25 \pm 7.64$ gm and 101.96 \pm 7.27 gm in group B (20-39 years), $95.59 \pm 0.75 \mathrm{gm}$ and $95.19 \pm 1.24$ gm in group C (40-59 years) (Table II). No significant difference was found between the weight of right and left kidneys in any group. However, statistically significant differences were evident for weight of kidney of each side among all age groups (Table II).

Table II: Weight of right and left kidney in different age group

\begin{tabular}{|c|c|c|c|}
\hline \multicolumn{4}{|c|}{ Weight in gram } \\
\hline Age group & $\begin{array}{c}\text { Right kidney } \\
\text { Mean } \pm \text { SD }\end{array}$ & $\begin{array}{c}\text { Left kidney } \\
\text { Mean } \pm \text { SD }\end{array}$ & p value \\
\hline $\begin{array}{c}\mathbf{A} \\
(\mathrm{n}=12)\end{array}$ & $\begin{array}{c}86.18 \pm 0.32 \\
(85.20-86.40)\end{array}$ & $\begin{array}{c}86.10 \pm 0.10 \\
(86.10-86.40)\end{array}$ & $>0.10 \mathrm{~ns}$ \\
\hline $\begin{array}{c}\text { B } \\
(\mathrm{n}=43)\end{array}$ & $\begin{array}{c}102.25 \pm 7.64 \\
(87.60-116.40)\end{array}$ & $\begin{array}{c}101.96 \pm 7.27 \\
(87.40-114.20)\end{array}$ & $>0.50 \mathrm{~ns}$ \\
\hline $\begin{array}{c}\mathbf{C} \\
(\mathrm{n}=15)\end{array}$ & $\begin{array}{c}95.59 \pm 0.75 \\
(94.50-96.50) \\
\text { p value }\end{array}$ & $\begin{array}{c}95.19 \pm 1.24 \\
(93.20-96.50) \\
\text { p value }\end{array}$ & $>0.10 \mathrm{~ns}$ \\
\hline A vs B & $<0.001 * * *$ & $<0.001 * * *$ & \\
\hline A vs $\mathbf{C}$ & $<0.001 * * *$ & $<0.001 * * *$ & \\
\hline B vs $\mathbf{C}$ & $<0.001 * * *$ & $<0.001 * * *$ & \\
\hline
\end{tabular}

Figures in the parentheses indicate range. Comparison between right and left side done by unpaired Student's ' $t$ ' test and comparison between different age groups done by One-way ANOVA (PostHoc). ns $=$ not significant, $* * *=$ significant. 


\section{Discussion}

Mullick ${ }^{9}$ examined 21 pairs of human kidney in a Bangladeshi population and found the average weight of the right kidney was $113 \mathrm{gm}$ and the left kidney 113.6 gm. Rao \& Wagner ${ }^{10}$ examined kidneys from 5 to 80 years subjects and stated that the weight of the kidneys were 65 to $131 \mathrm{gm}$ in males and 57 to $117 \mathrm{gm}$ in females. Darmady et al. ${ }^{8}$ studied on 105 human cadavers, age ranged from birth to 101 years, and found average weight of kidneys varied from 12 to 180 gm. Sultana ${ }^{7}$ examined 40 human kidneys and found the weight of the kidneys were $72.00 \pm 2.98 \mathrm{gm}$ and $51.33 \pm 0.88 \mathrm{gm}$ in group A (10-20 years), $96.33 \pm 6.50 \mathrm{gm}$ and $65.00 \pm 2.88 \mathrm{gm}$ in group $\mathrm{B}$ (21-40 years), $78.60 \pm 2.73 \mathrm{gm}$ and $49.50 \pm 0.05 \mathrm{gm}$ in group $\mathrm{C}$ (41-65 years) in male and female respectively. Alam ${ }^{11}$ studied on 60 postmortem kidneys and found average weight $54.6 \mathrm{gm}, 90.17$ gm and 88.5 gm in group A (5-15 years), B (16-35 years) and C (36-60 years) respectively. Èukuranović \& Vlajković ${ }^{4}$ found that the weight of the kidney declines from 250-270 gm at the age of 30-50 years followed by considerable weight loss from the age of 60 onwards. Banik ${ }^{12}$ studied 49 human kidneys and found that the weight of the right and left kidneys were $82.08 \pm 13.05 \mathrm{gm}$ and $82.16 \pm 13.06 \mathrm{gm}$ in group A (6-20 years), $100.05 \pm 6.78 \mathrm{gm}$ and $100.55 \pm 6.70 \mathrm{gm}$ in group B (21-36 years), $97.12 \pm 8.88$ gm and $95.08 \pm 7.94$ gm in group C (37-65 years) respectively. Nahar et al. ${ }^{13}$ studied 60 cadaveric kidneys of age ranging from 12 to 65 years and found the weight of the right and left kidneys $71.58 \pm 7.65 \mathrm{gm}$ and $71.58 \pm 7.27 \mathrm{gm}$ in group A (12-20 years), $101.54 \pm 1.38 \mathrm{gm}$ and $101.19 \pm 10.65 \mathrm{gm}$ in group B (21-40 years), 85.67 \pm 4.58 gm and $87.33 \pm 5.94$ gm in group C (41-65 years) respectively. McNamara et al. ${ }^{14}$ studied 81 postmortem kidneys of Senegalese Africans (62 adults and 19 children) and reported average kidney weight of $125.5 \pm 39.2$ gm in all $(\mathrm{n}=81)$, where as $138.6 \pm 31.2$ gm only in adults $(n=62)$. They also showed that kidney weight increased rapidly during childhood and adolescence, and appeared to decrease in late adulthood after the age of 60 years. Narongchai duo ${ }^{15}$ examined 449 autopsy cases (269 males and 230 females, aged between 15 and 60 years) and found the mean weight of the right kidney $106 \mathrm{gm}$ (male) and $97 \mathrm{~g}$ (female) and left kidney $112 \mathrm{gm}$ (male) and 98 gm (female). Khatun et al. ${ }^{16}$ studied on 50 cadaveric specimens and found the average weight of kidney $88.53 \mathrm{gm}, 95.25 \mathrm{gm}$ and 91.62 gm in group A (11-25 years), B (26-40 years) and C (41-80 years) respectively. Tărniceriu et al. ${ }^{2}$ indicated in their study that the kidney of a new born was 10-12 gm, increases at three years old to $50 \mathrm{gm}$ and continues to increase during the third-fourth decade to $150 \mathrm{gm}$ before decreasing to 115-140 gm by the seventh-eighth decade. However, some studies have other mathematical results than ours, but they reveal also the changes of kidney at different ages. Renal mass increases from $50 \mathrm{gm}$ at birth to $400 \mathrm{gm}$ during the third and fourth decades of life before decreasing to $300 \mathrm{gm}$ by the ninth decade. ${ }^{17,18}$ Molina \& DiMaio ${ }^{19}$ studied on 232 male subjects, aged 18-35 years, and found the mean weight of the right kidney was $129 \mathrm{gm}$ (ranged from 79 to $223 \mathrm{gm}$ ), and that of the left kidney was 137 gm (ranged from 74 to 235 gm). However, they proposed a reference value for male organ's weight as for right kidney 81-160 gm, and left kidney 83-176 gm. Apart from few exceptions, the results of the present study are similar to the previous records. The variations of kidney weight between Bangladeshi and western people might be because of higher body weight as well as greater body surface area in western population. ${ }^{16}$ In the course of aging, reduction of kidney weight is evident as there is a progressive loss of renal parenchyma i.e. one third to one half of renal nephrons is lost by old age. ${ }^{4}$

\section{Conclusion}

The weight of the kidney was found to increase up to 4 th decade of life and then declined with further advancing age. The results of the present study can 
be used as a standard reference weight for the kidneys of Bangladeshi people and to determine the abnormal evidences in forensic and pathologic corpses. Further studies with lager samples and comparison between sexes are recommended.

\section{Acknowledgement}

We would like to express our gratitude to the authority of Health, Nutrition \& Population Sector Programme (HNPSP) of Directorate General of Health Services (DGHS) of the Government of the People's Republic of Bangladesh, and Principal, Dhaka Medical College, Dhaka, for the research grant.

\section{References}

1. Epstein M. Aging and the Kidney. J Am Soc Nephrol. 1996;7(8):1106-22.

2. Tărniceriu CC, Goian L, Veliceasa B, Frâncu LL. Age Related Anatomical Changes of the Human Kidney. Rev Roman Anat Function Clin MacroMicros Antropol. 2011;10(4):432-38.

3. Lindeman RD, Goldman R. Anatomic and Physiologic Age Changes in the Kidney. Exp Gerontol. 1986;21(4-5):379-406.

4. Ėukuranović R, Vlajković S. Age Related Anatomical and Functional Characteristics of Human Kidney. Facta Universitatis Med Biol. 2005;12(2):61-69.

5. Papper S. The Effects of Age in Reducing Renal Function. Geriatrics.1973;28(5):83-87.

6. Kasiske BL, Umen AJ. The Influence of Age, Sex, Race, and Body Habitus on Kidney Weight in Humans. Arch Pathol Lab Med. 1986;10(1):55-60.

7. Sultana Z. An Anatomical Study of Human Postmortem Kidney in Bangladeshi People [thesis] Dhaka: IPGMR, University of Dhaka; 1991.

8. Darmady EM, Offer J, Woodhouse MA. The Parameters of the Ageing Kidney. J Pathol. 1973;109(3):195-207.
9. Mullick MH. A Comparative Study on Renal Arterial System in Man, Goat and Cow [thesis]. Dhaka: IPGMR, University of Dhaka; 1967.

10. Rao UVG, Wagner HN Jr. Normal Weights of Human Organs. Radiology. 1972;102(2): 337-39.

11. Alam MZ. Gross Morphological and Histological Features of Kidneys in Bangladeshi People [thesis]. Dhaka: IPGMR, University of Dhaka; 1994.

12. Banik S. Gross and Histomorphological Study of Human Postmortem Kidney in Bangladeshi People [thesis]. Dhaka: Sir Salimullah Medical College, University of Dhaka; 2005.

13. Nahar A, Hussain MA, Ara S, Begum J, Chowdhury AHMMM. Morphological Study of Postmortem Human Kidney. Bangladesh J Anat. 2007;5(1):10-14.

14. McNamara BJ, Diouf B, Hughson MD, Douglas-Denton RN, Hoy WE, Bertram JF. Renal Pathology, Glomerular Number and Volume in a West African Urban Community. Nephrol Dial Transplant. 2008;23(8):2576-85.

15. Narongchai P, Narongchai S. Study of the Normal Internal Organ Weights in Thai Population. J Med Assoc Thai. 2008;91(5):747-53.

16. Khatun H, Sultana Z, Islam NAF, Kibria GM, Chowdhury TE. Morphological Study of the Kidney in Relation to Age. Bangladesh $\mathrm{J}$ Anat. 2009;7(1):19-21.

17. Nyengaard JR, Bendtsen TF. Glomerular Number and Size in Relation to Age, Kidney Weight, and Body Surface in Normal Man. Anat Rec. 1992;232(2):194-201.

18. Tauchi H, Tsuboi K, Okutomi J. Age Changes in the Human Kidney of the Different Races. Gerontologia. 1971;17(2):87-97.

19. Molina DK, Di Maio VJ. Normal Organ Weights in Men: Part II - the Brain, Lungs, Liver, Spleen, and Kidneys. Am J Forensic Med Pathol. 2012;33(4):368-72. 